\title{
STRONG, THEREFORE SENSITIVE: MISGIVINGS ABOUT DEROSE'S CONTEXTUALISM
}

\author{
Jon COGBURN \& Jeffrey W. ROLAND \\ Lousiana State University
}

Summary

According to an influential contextualist solution to skepticism advanced by Keith DeRose, denials of skeptical hypotheses are, in most contexts, strong yet insensitive. The strength of such denials allows for knowledge of them, thus undermining skepticism, while the insensitivity of such denials explains our intuition that we do not know them. In this paper we argue that, under some well-motivated conditions, a negated skeptical hypothesis is strong only if it is sensitive. We also consider how a natural response on behalf of DeRose appears to be equally available to his primary rival (viz., the sensitivity theorist).

\section{Introduction}

Keith DeRose $(1995,2004)$ has advanced an influential contextualist solution to the skeptical problem. On contextualist accounts of knowledge, there are some contexts where one genuinely doesn't know whether one is (say) a brain in a vat and other contexts where one does know whether one is a brain in a vat. Part of what distinguishes DeRose's contextualist solution is the detailed and prima facie plausible story about how these contexts match some of the key intuitions that lead to the skeptical problem in the first place. For DeRose, epistemology must not just explain why the skeptic is wrong, but also why the skeptic sometimes seems right. Why is it sometimes so tempting to believe that, for all we know, we really might be BIV?

In brief, DeRose's answer is that skepticism sometimes seems to be right because negated skeptical hypotheses such as 'I am not a BIV' fail to have a certain modal property known as sensitivity (characterized below), and sensitivity is nearly correct as a third necessary condition of knowl-

1. We use the standard abbreviation, 'BIV' for 'brain in a vat' and cognate expressions. 
edge. As a result, we're tempted to say that we don't know the denials of skeptical hypotheses, and this opens the way for the skeptic's argument. However, for all its seeming rightness, skepticism is wrong according to DeRose because in most contexts negated skeptical hypotheses do have a certain other modal property, known as strength. So though for very good reasons it seems like we cannot know negated skeptical hypotheses, in fact we can.

Careful attention to the underlying modal principles produces an argument against this very aspect of DeRose's explanation of skeptical intuitions. Certain sorts of beliefs, arguably among them skeptical beliefs (i.e., beliefs that $p$, where $p$ is a skeptical hypothesis ${ }^{2}$ ), are such that there is no context where they are strong in DeRose's sense without also being sensitive. So DeRose is not entitled to the claim that negated skeptical hypotheses are both strong and insensitive. We begin $(\$ 1)$ by briefly setting out DeRose's solution to skepticism and introducing a framework for that solution. We continue $(\$ 2)$ with a discussion of how DeRose uses sensitivity to explain skeptical intuitions. Next $(\$ 3)$, we formulate and motivate a feature of skeptical beliefs which opens the way to a proof $(\$ 4)$ that sensitivity can't do the work DeRose asks of it. Finally $(\$ 5)$, we suggest ways in which the sensitivity theorist ${ }^{3}$ might be able to help herself to DeRose's deep insights into the role that context plays in epistemic evaluation.

\section{DeRose's contextualist solution}

\subsection{The skeptical argument}

For the duration of this paper, fix $H$ to be a generic skeptical hypothesis (e.g., 'An evil demon is deceiving me about nearly everything' or 'I am a BIV') and let $O$ be a statement expressing some ordinary contingent proposition that we typically take ourselves to unproblematically know (e.g., that I have hands). ${ }^{4}$ Then, as is common nowadays, the skeptical

2. We use lower-case, italicized roman letters (other than ' $w$ ') throughout as variables for declarative statements. We also sometimes blur the distinction between statements and propositions; no problems result from this blurring.

3. Throughout, we use 'sensitivity theorist' (and cognate expressions) as DeRose (2004) uses 'direct sensitivity theorist', roughly as one who takes knowledge to be true, sensitive belief.

4. We use upper-case, italicized roman letters (other than ' $C$ ' and ' $S$ ') throughout to represent particular declarative statements. We also often write as an individual to simplify examples. 
problem can be generated by the following skeptical argument.

(SA1) I don't know that $\neg H$.

(SA2) If I don't know that $\neg H$, then I don't know that $O$.

(SAC) Therefore, I don't know that $O$.

The skeptic affirms all three of these, and so holds (SA1), (SA2), and (SAC). Sensitivity theorists such as Robert Nozick (1981) affirm (SA1) yet try to deny (SA2) in order to deny (SAC), and so hold (SA1), $\neg$ (SA2), $\neg$ (SAC). And Mooreans such as Ernest Sosa $(1999,2000)$ deny (SA1) as a way to affirm (SA2) while denying (SAC), thus holding $\neg$ (SA1), (SA2), $\neg\left(\right.$ SAC). ${ }^{5}$

DeRose affirms (SA2) and then holds that epistemic context determines whether the skeptic or Moorean is correct. A strict epistemic context such as the typical philosophy classroom requires a lot from the knower, and for DeRose is one where skepticism is correct. On the other hand, permissive epistemic contexts such as the vast majority of mundane situations are ones where Mooreanism is correct. This is the payoff of DeRose's contextualism: in normal contexts, the Moorean is correct and skepticism is avoided; only in esoteric contexts is skepticism a threat.

\subsection{Strict versus permissive epistemic contexts}

One of the more distinctive components of DeRose's theory is the way in which it characterizes knowledge in terms of "strong enough true belief." In contrast to Sosa's safety account, ${ }^{6}$ DeRose writes:

The main difference is that ... [safety] is troubled only by worlds (especially very nearby worlds) in which one believes that $p$ but $p$ is not the case (ways in which $S$ would easily believe that $p$ without it being the case that $p$ ), while strength is disturbed both by that and by the presence of worlds (especially very nearby worlds) in which $p$ is true but $S$ disbelieves it. (DeRose 2004, 34)

Sosa helpfully characterizes DeRose's account in this manner:

5. There are interesting analogies to these positions in the philosophy of vagueness (Keefe 2007). If you consider the sorites paradox as an analogous inference (with many (SA2) steps), then: (1) the skeptic is the nihilist, (2) the sensitivity theorist the super (or sub) valuationist, and (3) the Moorean the epistemicist. Interestingly, one could model the contextualist's knowledge predicate using supervaluations, suggesting already an affinity between sensitivity theory and contextualism.

6. According to Sosa $(1999,2000)$, $S$ 's true belief that $p$ is knowledge for $S$ just in case it is safe: were $S$ to believe that $p$, it would be true that $p$. 
To know that $p$ is to believe that $p$ with enough "strength," where the strength of one's belief is stronger the more remote are any worlds wherein one first fails to match the fact of the matter as to whether $p$. That is to say, the strength of one's belief is directly proportional to the remoteness of the least remote worlds wherein it fails to be the case both that $[p \wedge B(p)]$ and that $[\neg p \wedge \neg B(p)]$. (Sosa 2004, 280)

In other words, the strength of $S$ s belief that $p$ is inversely proportional to the closeness of the nearest world where either $p \wedge \neg \operatorname{Bel}(S, p)$ or $\neg p \wedge \operatorname{Bel}(S, p)$ obtain. ${ }^{7}$ So, according to DeRose, my belief that I have hands is strong enough to count as knowledge because the closest worlds where I have hands and don't believe that I have hands, or where I lack hands and believe I have hands, are far distant from the actual world.

Though DeRose might himself find this unnatural, one can beautifully represent the way in which context partially determines strength in terms of counterfactual conditionals by rendering their semantics as linguists are likely to do, rather than according to the more common Lewisian approach favored by philosophers. In the natural language formal semantics and pragmatics literature (Kadmon 2001) it is much more usual to see something like this for counterfactual semantics:

LiNG $\square \rightarrow . p \square \rightarrow q$ is true in world $w$ and context $C$ just in case every $C$-relevant $p$-world is also a $q$-world. ${ }^{8}$

Here it is understood that $C$-relevance imposes a similarity metric such that $C$-relevant worlds are closer than non $C$-relevant worlds, and for any such metric the actual world is the closest world. This approach is closely connected to the Lewisian approach to counterfactual semantics more commonly followed by philosophers-where $p \square \rightarrow q$ is true in world $w$ and context $C$ just in case the closest $C$-relevant $p$-world is also a $q$-world —in that, if $p \square \rightarrow q$ holds in the linguists' sense, it will also hold in the philosophers' sense.

The linguists' approach is particularly well suited to DeRose's concept of strength for a couple of reasons. First, by using it we can define strength without facing what DeRose (2004) has called the "true-true problem" that besets standard explications of safety-based epistemology. ${ }^{9}$

7. We use ' $\operatorname{Bel}(S, p)$ ' to abbreviate ' $S$ believes that $p$ '.

8. We follow convention in using $\square \longrightarrow$ as a connective for the counterfactual conditional.

9 For the true-true problem, see (DeRose 2004). 
Strength. $S$ 's belief that $p$ is strong in context $C$ if and only if $p \square \rightarrow$ $\operatorname{Bel}(S, p)$ and $\operatorname{Bel}(S, p) \square \longrightarrow p$ are true in $C$.

This definition avoids the true-true problem because (Ling $\square \longrightarrow$ ) makes sense of false counterfactual conditionals with true antecedents, something the Lewisian approach cannot do. This is essential because of course one might have a true belief that fails to be knowledge, but on the Lewisian account the actual truth of $S$ 's belief, combined with the fact that $S$ does actually believe that $p$, trivially renders both $p \square \rightarrow \operatorname{Bel}(S, p)$ and $\operatorname{Bel}(S, p)$ $\square \rightarrow$ true. $^{10}$

Second (and this is certainly why they tend to characterize the underlying semantics in this manner), the linguists' semantics allows for much more elegant characterization of the way context selects for varying kinds and strengths of modality. ${ }^{11}$ We can use it to define epistemic context $C$ as being more permissive than epistemic context $C^{\prime}$ (equivalently that $C^{\prime}$ is stricter than $C$ ) if the $C$-relevant worlds are a proper subset of the $C^{\prime}$-relevant worlds. Then for example, $p$ could be strong relative to $C$ and weak relative to $C^{\prime}$. The more worlds an epistemic context rules in as relevant for consideration, the stricter that context.

10. One can solve the true-true problem while continuing to utilize Lewisian semantics by giving up strong centering, according to which the actual world is uniquely closest to itself. Weak centering, by contrast, still holds that no world is closer to the actual world than itself, but permits non-actual worlds to be equally close. Such worlds might be ones where a counterfactual conditional with actually true antecedent and consequent has a true antecedent and false consequent. We don't opt for this solution for three reasons.

First, the linguists' semantics presented here avoids the true-true problem without having to sacrifice centering. Second, in (Cogburn and Roland MS) we argue that recent versions of Sosan safety-based accounts should follow linguists more generally and take conditionals as generalized quantifiers over possible worlds. So comparing strength-based and safety-based accounts is much easier if we use an instance of this scheme in modeling DeRose, as we have here. Third, as far as we can tell it's more difficult to logically regiment DeRose's theory using Lewisian semantics with weak centering (and without strong centering). On the weak centering version of Lewisian semantics, the truth or falsity of a counterfactual is still determined by what happens in one set of worlds equidistant from the actual world. But on DeRose's theory the strength of a belief in a context is a function of the truth of two conditionals in a set of non-equidistant worlds picked out by the context, with the subset relation (as opposed to "closer than") on such sets of worlds mirroring levels of strength required by context. As we show below, the linguists' semantics captures this exactly. We thank an anonymous referee for encouraging us to expand on this point.

11. See, e.g., the ground-breaking work in (Kratzer 1977) and (Roberts 1989), respectively on the characterization of conditionals as generalized quantifiers over possible worlds and on how modal subordination is an instance of domain selection more broadly. 
This allows us to make clear sense of DeRose's contextualism. Suppose, as is standard in the contemporary epistemology literature, we are not in fact BIV and that by any reasonable epistemic metric worlds where we are BIV are very dissimilar to (distant from) the actual world. A very strict epistemic context $C^{*}$ would rule in so many worlds that the class of $C^{*}$ relevant worlds would include worlds where either I'm not a BIV and I believe that I am (making $\neg H_{b i v} \square \rightarrow \operatorname{Bel}\left(S, \neg H_{b i v}\right)$ false in $C^{*}$, where $H_{b i v}$ is the hypothesis 'I'm a BIV') or worlds where I believe that I'm not a BIV but I am one (making $\operatorname{Bel}\left(\mathrm{S}, \neg H_{b i v}\right) \square \rightarrow \neg H_{b i v}$ false in $\left.C^{*}\right){ }^{12}$ In contexts such as $C^{*}$, ordinary beliefs such as that I have hands are just as likely to not be strong (since DeRose accepts the skeptical inference, (SA2)). For DeRose, the philosophy classroom tends to select such contexts. On the other hand, a more permissive epistemic context would rule in far fewer relevant worlds, excluding worlds where competent epistemic agents either fail to believe they have hands or believe they have hands even though they don't. So where $O$ expresses the proposition that $S$ has hands, both $O \square \rightarrow \operatorname{Bel}(S, O)$ and $\operatorname{Bel}(S, O) \square \rightarrow O$ are true in permissive contexts. Likewise, given the validity of (SA2) on DeRose's account, $S$ 's belief that $\neg H_{b i v}$ is also strong in permissive contexts, as there is no world in the restricted set either where $S$ is not a BIV and she fails to believe that she is not or where $S$ believes she is not a BIV and she in fact is. That is, both $\neg H_{b i v} \square \rightarrow \operatorname{Bel}\left(\mathrm{S}, \neg H_{b i v}\right)$ and $\operatorname{Bel}\left(\mathrm{S}, \neg H_{b i v}\right) \square \rightarrow \neg H_{b i v}$ are true in permissive contexts.

\section{Sensitivity and insensitivity}

Our use of linguists' account of counterfactual semantics enables us to recapitulate DeRose's contextualism entirely in terms of the strength of a belief. Whether one epistemic context $C$ is stricter than another $C^{\prime}$ depends entirely on the set of possible worlds which are relevant to assessing the truth of the strength counterfactuals in $C$ being a proper superset of the set of worlds which are relevant to assessing the truth of those counterfactuals

12. Notice that if one understood belief so that an agent believes every consequence of her beliefs, then we would need to add a consistency constraint on belief sets or adopt a paraconsistent logic in order for the first of these counterfactuals to be false in $C^{*}$. (See p. 13 for discussion related to the paraconsistency option.) However, we take it that the notion of belief operative in these debates isn't closed under consequence in the way indicated. Thanks to an anonymous referee for raising this issue. 
in $C^{\prime}$. This is sufficient to model the contextualist's view that skepticism is correct in strict epistemic contexts and incorrect in more permissive ones.

DeRose, however, adds another commitment to this picture. He holds that epistemic contexts strict enough to support (SA1) will be ones where the negated skeptical hypothesis $\neg H$ is insensitive in Nozick's (1981) sense. For the sensitivity theorist, $S$ knows that $p$ just in case $S$ 's belief that $p$ is true and sensitive, in that were $p$ false then $S$ would not believe that $p$. That is, $S$ 's belief that $p$ is sensitive just in case $\neg p \square \rightarrow \neg \operatorname{Bel}(S, p)$ is true. On the other hand, $S$ 's belief that $p$ is insensitive just in case $\neg p \square \rightarrow \operatorname{Bel}(S, p)$ is true. That something like sensitivity is a necessary condition for knowledge is a redoubtable intuition in epistemology, arguably going back as far as (Russell 1912/1997). It is so redoubtable that both Sosa $(1999,2000)$ and DeRose take it to be one of the tasks of epistemology to explain why people are drawn to it. For Sosa, the fact that the counterfactual conditional expressing sensitivity is the contraposition of his own safety condition, plus the fact that contraposition is valid for material conditionals but not counterfactuals (on the Lewisian semantics), ${ }^{13}$ explains why people wrongly think sensitivity is a necessary condition on knowledge. But then, for Sosa, this explains why people wrongly think that we do not know the denials of skeptical hypotheses, since (according to DeRose and Sosa) the denial of a skeptical hypothesis is insensitive (i.e., $H \square \rightarrow \operatorname{Bel}(S, \neg H)$ is true).

DeRose agrees that it is the insensitivity of negated skeptical hypotheses that leads us to conclude that we do not know skeptical hypotheses to be false.

Suppose a direct sensitivity theorist uses the phenomena I've cited as reasons for thinking that [the subjunctive conditional account] is on the right track as support for the view knowledge is roughly true, sensitive believe (with perhaps some other necessary conditions for knowledge also thrown in, to taste). Such a theorist may think there is an important property of beliefs, sensitivity*, which is necessary for knowledge, and of which the conditionals in terms of which sensitivity is defined give a good first approximation. (DeRose 2004, 28)

13. We should note that the semantics we use in this paper for DeRose's account validates contraposition, but nothing hangs on this. Our use of $\square \rightarrow$ here only formalizes DeRose's modal notion of strength. Nothing we say presupposes that sensitivity or safety theorists must use a contraposing notion of counterfactuals. In particular, the relevant sort of sensitivity claim to which we will argue DeRose is committed can be stated using sensitivity theorists' preferred semantics for counterfactuals. See n. 17. 
DeRose argues that both he and Sosa should be committed to this.

We both appeal to certain beliefs' insensitivity to explain why they give an appearance of no-knowledge, but we both do so in an indirect way: Neither of us pictures knowledge as being anything like sensitive true belief, so we both must explain why insensitive beliefs so often seem not to be knowledge even when they have what we claim is the real knowledge-making property (safety, strength) to a high degree. (DeRose 2004, 35)

However, DeRose diverges from Sosa precisely in the explanatory role that contextualism plays here.

I believe that a contextualist version of the picture of knowledge under consideration can provide a powerful explanation of why insensitive beliefs can so often give an appearance, of no-knowledge, even when they are quite strong, and can thereby provide a powerful solution to the particular skeptical paradox that both Sosa and I wrestle with. (DeRose 2004, 35)

For DeRose, it is precisely because negated skeptical hypotheses are both insensitive and "quite strong" that the skeptical problem is so alluring. But this is precisely where problems arise for his view.

\section{Evidential indistinguishability}

Say that propositions $p, p^{\prime}$ are evidentially indistinguishable just in case there are no experiences one might have such that on the basis of those experiences one could rationally judge $p$ to be true and $p^{\prime}$ to be false. Propositions are evidentially distinguishable just in case they're not evidentially indistinguishable. Lots of propositions are clearly evidentially distinguishable (e.g., the proposition that there is a cat on the mat and the proposition that water boils at room temperature). Moreover, lots of propositions are evidentially distinguishable from their denials. The proposition that there is a cat on the mat is clearly such a proposition. Intuitively, evidentially indistinguishable propositions are equally well confirmed by any experiences relevant to their confirmation. ${ }^{14}$ We can make the notion of evidential indistinguishability more precise as follows. Let an agent $S$ 's evidential base for a proposition $p$ be the sum total of $S$ 's experiences that bear on the truth value of $p$. A proposition is confirmed for an agent $S$ if and only if $S$ 's evidential base for $p$ makes it rational for $S$ to judge $p$ to

14. Cf. empirically equivalent theories. 
be true. Then propositions $p, p^{\prime}$ are evidentially indistinguishable if and only if $p \wedge \neg p^{\prime}$ is not confirmed for any agent. ${ }^{15}$

What's important for present purposes is that one of the signature properties of propositions expressed by skeptical hypotheses such as 'I am a BIV' is that they are by design supposed to be evidentially indistinguishable from their denials. Suppose $H$ is a true skeptical hypothesis. According to the skeptic there is no experience that could warrant the assertion that $H$, just because all experience is by design systematically misleading on this very score. So there is no confirming evidential base for the proposition that $H$. This would not be of great moment if it were any easier to confirm the proposition that $\neg H$. For if we could confirm that, then the evidential base favoring it would be a straight refutation of skepticism. So any self-respecting skeptical hypothesis must at least attempt to be one such that if it is false, no experience could warrant the assertion that it is false, i.e., no evidential base confirms the proposition that it's false. Put another way, $H$ and $\neg H$ are evidentially indistinguishable just in case there is no confirming evidential base for $H \wedge \neg \neg H$. But a confirming evidential base for $H \wedge \neg \neg H$ would be a confirming evidential base for $H$. However, again, there is no confirming evidential base for $H$ by design. So $H$ and $\neg H$ are evidentially indistinguishable.

Now, obviously, just because the skeptic intends skeptical hypotheses to be evidentially indistinguishable from their denials, we don't need to accept that they in fact are. But we should accept that one needs an argument for evidential distinguishability, since skeptical hypotheses certainly do at least give a strong impression of being evidentially indistinguishable from their denials. If no evidence whatsoever could hold in favor of $p$, it's very hard to see how any evidence whatsoever could hold against $p$. This entails that if a proposition that is evidentially indistinguishable from its negation is indeed sensitive, then the negation of that proposition should be sensitive as well. This is easiest to see if we back up and consider the intuition that sensitivity is designed to capture, that true beliefs that fail to be knowledge do so precisely because they involve luck. Now suppose that the proposition that it is two o'clock is for Sam evidentially indistinguishable from the proposition that it is not two o'clock. This means Sam

15. This dependence on agents and experiences gives that the evidential indistinguishability of propositions may vary over time or worlds, which seems to us as it should be. What's important for present purposes is that skeptical hypotheses and their denials are stably evidentially indistinguishable. As we'll see in the next section, this very fact underwrites DeRose's claim that skeptical hypotheses and their denials are stably insensitive. 
has equal access to information that could confirm either proposition with equal reliability. But then Sam is just as unlikely to be lucky with respect to the belief that it is two o'clock as he is with respect to the belief that it is not two o'clock. This has the consequence that the sensitivity theorist understands the counterfactual 'were it not the case that it is two o'clock, then Sam would not believe it is two o'clock' as entailing 'were it not the case that it is not two o'clock, then Sam would not believe that it is not two o'clock'. The absence of luckiness that justifies the claim that his belief that it is two o'clock is sensitive also justifies the sensitivity of his belief that it is not two o'clock (did he in fact believe that). So if a proposition and its negation are evidentially indistinguishable from one another, it follows that the sensitivity of one entails the sensitivity of the other.

We should repeat that we don't take ourselves to have definitively established that skeptical hypotheses are in fact evidentially indistinguishable from their denials (though we argue below that DeRose is committed to this being the case). All we've tried to show is that the view that a given skeptical hypothesis is evidentially distinguishable from its denial requires an argument, and that if skeptical hypotheses are evidentially indistinguishable from their denials, then they and their denials succeed or fail together to be sensitive-either both are sensitive or neither is.

\section{Strength entails sensitivity}

The evidential indistinguishability of skeptical hypotheses and their denials undermines DeRose's contention that the denial of a skeptical hypothesis can be strong yet insensitive. This, in turn, undermines achievement of one of his main goals: the attempt to harness sensitivity theory to explain the intuitive attraction of skepticism. The proof that strength entails sensitivity is a fairly straightforward piece of logic that requires only one additional premise of any potential controversy, which we now introduce. Say that an agent $S$ is a member of the laity (to be contrasted with the Priesthood, see e.g. (Priest 2002)) with respect to $p$ if and only if, necessarily, if $S$ believes that $p$ is false, then $S$ does not believe that $p$. We formalize this as

$$
\text { LAITY. } \forall p \forall S[L a(S, p) \leftrightarrow \square(\operatorname{Bel}(S, \neg p) \rightarrow \neg \operatorname{Bel}(S, p))]
$$

Let $H_{b i v}$ be the BIV hypothesis and assume that DeRose is a member of the laity with respect to $H_{b i v}$. As far as we know, no one has defended the 
view that skeptical hypotheses are the kind of statements one could both disbelieve and believe. If one could motivate dialetheism with respect to skeptical beliefs, then it would not be an obviously crazy position (just as it is not an obviously crazy position with respect to statements such as 'This statement is false'). But even with the background of self-reflexive epistemic paradoxes, ${ }^{16}$ dialetheism with respect to skeptical beliefs has not been defended. So we take ourselves to be justified in assuming that DeRose is a member of the laity with respect to $H_{b i v}$.

The proof begins with one half of the definition of DeRosean strength and DeRose's claim that the denial of $H_{b i v}$ is strong.

1. $\forall p \forall S[\operatorname{Str}(p, S) \rightarrow(p \square \rightarrow \operatorname{Bel}(S, p))]$ (by Strength).

This just says that for all statements $p$ and agents $S$, if $p$ is strong for $S$, then $p \square \rightarrow S$ believes that $p$ holds in the sense of (Ling $\square \longrightarrow$ ). Then we have:

2. $\operatorname{Str}\left(\neg H_{b i v}, d\right)$ (DeRose's assumption),

which just says that the denial of $H_{b i v}$ is strong for DeRose. These two together entail the following:

3. $\operatorname{Str}\left(\neg H_{b i v}, d\right) \rightarrow\left(\neg H_{b i v} \square \rightarrow \operatorname{Bel}\left(d, \neg H_{b i v}\right)\right)$ (from 1, by $\forall$ elimination), 4. $\neg H_{b i v} \square \operatorname{Bel}\left(d, \neg H_{b i v}\right)$ (from 2 and 3 , by $\rightarrow$ elimination).

Then from (Laity) and the claim that DeRose is a member of the laity with respect to $H_{b i v}$ we get:

5. $\forall p \forall S[L a(S, p) \rightarrow \square(\operatorname{Bel}(S, \neg p) \rightarrow \neg \operatorname{Bel}(S, p))]$ (by Laity),

6. $L a\left(d, H_{b i v}\right)$ (assumption),

7. $L a\left(d, H_{b i v}\right) \rightarrow \square\left(\operatorname{Bel}\left(d, \neg H_{b i v}\right) \rightarrow \neg \operatorname{Bel}\left(d, H_{b i v}\right)\right.$ ) (from 5, by $\forall$ elimination),

8. $\square\left(\operatorname{Bel}\left(d, \neg H_{b i v}\right) \rightarrow \neg \operatorname{Bel}\left(d, H_{b i v}\right)\right.$ (from 6 and 7 , by $\rightarrow$ elimination).

16. See (Sundholm 2008), an essay titled "A Novel Paradox?" One of the present authors must respond with an emphatic "No!" The same epistemic paradox is discussed at length in (Cogburn 2004), where in a footnote the author credits himself and Roy Cook with having jointly discovered it in the mid 1990s. Of course, it is not improbable that someone else discovered it prior to that, and all such discussions rest on the shoulders of others (Kaplan and Montague 1960). But it is notable that the paradox of Cogburn and Cook does not require epistemic closure. 
So on (4) we have that if $H_{b i v}$ were false, it would be the case that DeRose believes that it is false, and on (8) we have that necessarily if DeRose believes $H_{b i v}$ to be false, then he does not believe $H_{b i v}$. By the following weak transitivity principle for counterfactuals,

WTC. $p \square \rightarrow q, \square(q \rightarrow r) \vdash p \square \mapsto r$,

it therefore follows that,

$$
\text { 9. } \neg H_{b i v} \square \rightarrow \neg \operatorname{Bel}\left(d, H_{b i v}\right) \text { (from } 4 \text { and } 8 \text {, by WTC). }
$$

But this is just to say that $H_{b i v}$ is sensitive for DeRose. ${ }^{17}$ Hence, our proof shows that if the denial of $H_{b i v}$ is strong (as DeRose claims), then $H_{b i v}$ itself is sensitive.

The sensitivity of $H_{b i v}$ is a problem for DeRose. He likes to characterize the insensitivity of an agent $S$ 's belief that $p$ as a "block" to judging that $S$ knows that $p$, and he argues that the fact that many cases of no-knowledge can be modified so that

(a) they flip from no-knowledge to knowledge cases, and

(b) the relevant belief flips from insensitive to sensitive

is evidence that his account of the attractiveness of skeptical hypotheses is on the right track.

Consider, for instance, a standard lottery case in which (prior to the winning numbers being announced) we judge that we don't know that our ticket will lose. DeRose identifies the insensitivity of our belief that we will lose (i.e., the truth of the counterfactual 'were we to have the winning ticket we would believe that we didn't') as the block to judging that we know we will lose. After the winning numbers have been announced, however, and they indeed aren't the numbers on our ticket, we would like to say that we know we have a losing ticket. But we also would no longer

17. One might object that line (9) of the above proof is not in fact a statement of sensitivity, since sensitivity theorists intended something different by the counterfactual conditional than what we are calling the linguists' account. Such an objection has no purchase however, as $p \square \rightarrow q$ in the sense given in the above proof entails $p \square \rightarrow q$ understood in sensitivity theorists' preferred sense, whether Lewisian or in terms of generalized quantification over most of some set of contextually selected worlds, as we argue one should prefer in the context of safety theory (Cogburn and Roland MS). 
say that were we to have the winning ticket we would believe that we didn't. Rather, we'd say that a different counterfactual is true, viz., 'were we to have the winning ticket, we would not believe that we have a losing ticket'. But this is just to say that the belief that we have a losing ticket is sensitive. The block has been removed. From this example and others similar to it, DeRose concludes:

Again and again, [my account] posits a certain block to our judging that we know, and the changes that would clear the way for our judging that we know also remove this block. This makes it difficult not to believe that [my account] is at least roughly correct. (DeRose 1995, 25)

The situation is different for skeptical hypotheses.

In the case of the BIV hypothesis, it's hard to test [my account] in this way, for it's difficult to imagine a situation in which it seems a subject does know that she's not a BIV. But this only confirms [my account]: While it's difficult to imagine a situation in which one seems to know that one's not a BIV, it's likewise difficult to imagine circumstances in which the block [my account] posits is removed. It's difficult, that is, to imagine a situation in which someone believes they're not a BIV but in which the conditional If $S$ were a BIV, then $S$ would believe she wasn't a BIV isn't true. For, as the BIV hypothesis is formulated, one's brain is electrochemically stimulated so that one has precisely those sensory experiences one actually has had. But wouldn't one then have formed precisely those beliefs that one actually has formed, including the belief that one's not a BIV? (DeRose 1995, 25f., original emphasis)

DeRose's point here is that, in contrast to non-skeptical cases, it appears that cases involving skeptical hypotheses cannot be modified so as to satisfy (a) and (b) above. The result of not being able to satisfy (b) with respect to skeptical cases is that negations of skeptical hypotheses are stable with respect to insensitivity - it appears they can't be flipped from insensitive to sensitive. In particular, $S$ 's belief that $\neg H_{b i v}$ is stably insensitive. For our purposes, there are two important things to notice about the argument of this passage.

First, the argument of this passage applies equally well to an agent's belief that $H_{b i v}$ (were she to have such a belief). Just as it's hard to imagine a situation in which someone believes they're not a BIV but in which the conditional 'If $S$ were a BIV, then $S$ would believe she wasn't a BIV' isn't true, it's hard to imagine a situation in which $S$ believes she is a BIV (i.e., $\left.\operatorname{Bel}\left(S, H_{b i v}\right)\right)$ but in which the conditional 'If $S$ weren't a BIV, then $S$ would believe she was a BIV' isn't true-and for the very same reasons. 
By design, $H_{b i v}$ guarantees that $S$ will have had the same sensory experiences as she has actually had at every $C$-relevant world, and so it seems she should also have the same beliefs as she actually has, including the belief that she's a BIV. So in every $C$-relevant world, the consequent of $\neg H_{b i v} \square \rightarrow \operatorname{Bel}\left(S, H_{b i v}\right)$ is true, and thus so is the counterfactual itself. It follows that $H_{b i v}$ is stably insensitive. But then $H_{b i v}$ is not sensitive, contrary to (9). DeRose appears to be caught in a contradiction.

Moreover, even if this contradiction is merely apparent (and this is the second thing to notice), the reasoning DeRose deploys in support of the stable insensitivity of $S$ 's belief that $\neg H_{b i v}$ relies on the evidential indistinguishability of $H_{b i v}$ and $\neg H_{b i v}$. If $S$ has precisely the same sensory experiences in BIV worlds and non-BIV worlds, as DeRose contends, then no sensory experience will allow $S$ to distinguish between BIV and non-BIV worlds. Thus DeRose himself countenances the evidential indistinguishability of $H_{b i v}$ and $\neg H_{b i v}$. But then we have:

$$
\begin{aligned}
& \text { 10. } \neg \neg H_{b i v} \square \longrightarrow \neg \operatorname{Bel}\left(d, \neg H_{b i v}\right) \text { (from 9, evidential indistinguishability } \\
& \text { of } H_{b i v} \text { and } \neg H_{b i v} \text {. }
\end{aligned}
$$

Q.E.D. Hence, if $\neg H_{b i v}$ is strong, then it is also sensitive. But there's nothing special here about $\neg H_{b i v}$. So this result generalizes to all skeptical hypotheses. ${ }^{18}$

So, unless one has a compelling story about why skeptical hypotheses fail to be evidentially indistinguishable from their denials (and not only have we not seen anyone argue for anything that would entail the relevant distinguishability, DeRose appears unable to avail of himself of such an argument were it to be given), or unless one defends dialetheism with respect to skeptical hypotheses (again, we haven't seen such a defense) one cannot hold, as DeRose does, that the denial of skeptical hypotheses are simultaneously strong and insensitive. Something's got to give.

\section{Concluding remarks}

The easiest way for DeRose to respond would be to simply abandon the idea that the insensitivity of negated skeptical hypotheses plays an impor-

\footnotetext{
18. Thanks to an anonymous referee for pressing us on the move from (9) to (10) and its connection to evidential indistinguishability, as well as on the status of (9) itself.
} 
tant role in explaining skeptical intuitions. This seems promising to us. Why can't the contextualist idea that in some epistemic contexts skeptical hypotheses are known to be false and in some contexts they're not be enough of an explanation for the perennial draw of skepticism? And, as is clear from our discussion in $\$ 1$, DeRose's picture of how this works suggests a formal model that is clear and intuitively compelling.

Sorting this out would take some work though. For if one accepts that negated skeptical hypotheses are sensitive, then one has to accept that the sensitivity theorist has the resources to combat skepticism. Since the supposed failure of sensitivity theory to combat skepticism serves as one of the principal reasons for preferring both safety theory and DeRose's theory of strength to sensitivity theory, this raises the issue of the extent to which the formal model from $\$ 1$ is nothing more than epicycles. Why all the bother with strength and safety if sensitivity theory undermines skepticism in any case?

The contextualist should double down here. Strength is not an absolute notion, and indeed the formal characterization in $\$ 1$ starts with the characterization of what it is for one context to be stricter than another in terms of inclusion of relevant sets of possible worlds. The same belief then can be strong in a permissive context and weak in a strict one. But if this is the understanding of the underlying modal semantics, the DeRosean would interpret the formal derivation in the previous section in a very specific manner. The claim that a negated skeptical hypothesis is strong is the claim that certain material conditionals hold across a suitably permissive set of possible worlds, a set selected by the linguistic and epistemic context in which the negated skeptical hypothesis is asserted. But then, to avoid equivocation, the conclusion that the negated skeptical hypothesis is sensitive must also be understood using the same set of contextually determined worlds. So all we've really established is that, for DeRose, any context in which a non-Priestly belief that is also evidentially indistinguishable from its negation ${ }^{19}$ is strong is also a context in which that belief is sensitive. But this is consistent with there being other contexts where the same belief is insensitive.

By the proof of $\$ 4$, contexts in which a negated skeptical hypothesis is insensitive will also be contexts where it is not strong. So, again, the claim that a belief is strong yet insensitive still cannot be used by DeRose to explain skeptical intuitions. For DeRose it really is the relativization of

19. Beliefs are evidentially indistinguishable just in case their propositional contents are. 
the notion of strength to context, such that a belief can be strong in some contexts and not in others, that ends up doing all of the work. He should say that skepticism often seems right because in some (strict) contexts we do not know skeptical hypotheses to be false, and then use strength to explain how this works.

This being said, we would be remiss not to conclude with a mihi quoque argument on behalf of the sensitivity theorist. If the characterization of strictness of context in terms of nested sets of possible worlds is doing all of the work for DeRose, then there is no reason the sensitivity theorist could not adopt the same contextualist modal semantics for her own account of knowledge. But then, the alleged problems with sensitivity theory weren't something to be fixed by replacing it with some cognate notion like safety or strength, but rather by accepting the contextualism of some defenders of these two notions. Of course, fully defending such a position would be another endeavor, but the fact that the sensitivity theorist can now argue that the strength theorist is already committed to a contextualist sensitivity theory with respect to skeptical hypotheses (in that negated skeptical hypotheses are sensitive in some contexts and not in others, exactly corresponding to whether they are strong or not strong in those very same contexts) is already some evidence in its favor. For the sensitivity theorist is in an excellent position to avail herself of DeRose's insights into the nature of epistemic context without what should now appear to her to be DeRose's and Sosa's modal epicycles. ${ }^{20}$

\section{REFERENCES}

Cogburn, Jon 2004: "Paradox Lost". Canadian Journal of Philosophy 34, 195-216.

Cogburn, Jon \& Roland, Jeffrey W. (unpublished): "Safety and the True-True Problem". Unpublished manuscript.

DeRose, Keith 1995: "Solving the Skeptical Problem". Philosophical Review 104, 1-52.

- 2004: "Sosa, Safety, and Skeptical Hypotheses". In: John Greco (ed.), Sosa and His Critics. Oxford: Blackwell Publishers, 22-41.

Kadmon, Nirit 2001: Formal Pragmatics. Malden: Wiley-Blackwell.

Kaplan, David \& Montague, Richard 1960: "A Paradox Regained". Notre Dame Journal of Formal Logic 1, 79-90.

20. Thanks to two anonymous referees for this journal for valuable comments. 
Keefe, Rosanna 2007: Theories of Vagueness. Cambridge: Cambridge University Press.

Kratzer, Angelika 1977: "What 'Must' and 'Can' Must and Can Mean”. Linguistics and Philosophy 1, 337-355.

Nozick, Robert 1981: Philosophical Explanations. Cambridge, MA: Harvard University Press.

Priest, Graham 2002: In Contradiction: A Study of the Transconsistent. Oxford: Oxford University Press.

Roberts, Craige 1989: "Modal Subordination and Pronominal Anaphora in Discourse". Linguistics and Philosophy 12, 683-721.

Russell, Bertrand 1912/1997: The Problems of Philosophy. Oxford: Oxford University Press.

Sosa, Ernest 1999: "How to Defeat Opposition to Moore". Philosophical Perspectives 13, 141-153.

- 2000: "Skepticism and Contextualism". Philosophical Issues 10, 1-18.

- 2004: "Reply to Keith DeRose". In: John Greco (ed.), Sosa and His Critics. Oxford: Blackwell Publishers, 276-282.

Sundholm, Göran 2008: “A Novel Paradox?” In: Cedric Dégremont, Laurent Kieff \& Helge Rückert (eds.), Dialogues, Logics and Other Strange Things: Essays in Honour of Shahid Rahman. London: College Publications, 375-378. 